\title{
HOMENAGEM
}

\section{"O SOL NASCE PARA TODOS" JOSÉ RIBEIRO PORTUGAL - PAI DA NEUROCIRURGIA BRASILEIRA}

\author{
MARIO BROCK*
}

\author{
Prezados colegas, membros da Academia Brasileira de Neurocirurgia! Autoridades presentes! Senhoras e \\ Senhores!
}

José Ribeiro Portugal nasceu na sexta-feira, dia 26 de julho de 1901, no lugarejo mineiro de Santa Rita do Sapucaí. Aprendeu a ler aos 8 anos de idade. Aos 32 tinha cem leitos de neurocirurgia.

Quis a generosidade dos dirigentes da Academia Brasileira de Neurocirurgia, que coubesse a mim a honra de relembrar hoje e aqui este vulto gigantesco, pai da neurocirurgia brasileira e uma das personalidades mais marcantes da neurocirurgia sul-americana e mundial deste século.

Acredito-me legitimado para a desincumbência desta honrosa tarefa, pois fui discípulo do Prof. Portugal de 1957 a 1964. Não sei se o mestre teve outro discípulo cotidiano por tão longo período de tempo, mas estou convencido de que com nenhum o contacto foi tão intenso e imediato. Não apenas os dias úteis, mas também os meus fins de semana eram dedicados ao Professor Portugal. Para aprender o mais possível, era necessário não perder de vista $o$ mestre um segundo sequer. lamos juntos à sua fazenda, no seu Mercedes preto, de assentos estofados de couro cinza claro. Zélio, chofer devoto e seguro, cuidava da rota enquanto o jovem estagiário crivava o mestre de perguntas sobre os casos da semana e sobre as coisas da vida. Chegados à fazenda, geralmente na sexta-feira à tarde, o Professor Portugal dava as instruçōes ao capataz, fazíamos um jantar frugal e jogávamos uma partida de buraco antes de nos recolhermos. Obviamente, cabia a mim, discípulo respeitoso, perder a partida. Em um desses numerosos fins de semana, em abril de 1964, foi feita por mim a fotografia que ilustra este trabalho (Figura 1).

Um dos grandes prazeres do menino Portugal era apoderar-se do ferro de engomar a brazas de carvão de sua māe depois que esta havia teminado de passar roupa. Com o auxílio de um barbante, Portugal pendurava o ferro num galho de um limoeiro do sítio em que nasceu e fazia balançar o limoeiro, de modo que o ferro de engomar oscilasse e a fumaça que dele saía simulasse a locomotiva do trem que uma vez por semana passava pela recôndita Santa Rita do Sapucaí. Filho de Antonio Ribeiro Portugal e Maria do Carmo Ribeiro Portugal, o menino José Portugal economizava a sua mesada para poder comprar uma garrafa de cachaça que presenteava ao maquinista da ferroviária a fim de que este acionasse $o$ apito da locomotiva no momento em que o trem desaparecia atrás da colina ao deixar Santa Rita do Sapucaí. Com que saudade e poesia Portugal me narrou episódios de sua vida!

Bem cedo se definem as características marcantes deste vulto da nossa especialidade: um senso interminável de poesia, um espiríto inventor, um caráter inovativo e, sobretudo, uma alma profundamente humana. Desta generosidade tive prova um dia, mais ou menos por volta de 1958, quando, como jovem estagiário, sem padrinhos e sem "pistolōes", perguntei ao mestre quais seriam, a seu ver, as minhas oportunidades profissionais. Portugal olhoume com aquele olhar típico, pessoal, inconfundível, olhar-abraço, olhar-amigo, olhar-companheiro, olhar-protetor e disse:

"Mário, o sol nasce para todos".

Oraçāo proferida em 8 de agosto de 1993 durante a solenidade de abertura do V Congresso da Academia Brasileira de Neurocirurgia: *Cátedra de Neurocirurgia, Universitätsklinikum Steglitz, Freie Universität Berlin, Alemanha.

Prof. Dr. med. Mario Brock - Neurochirurgische Klinik, Universitätsklinikum Steglitz - Hindenburgdamm 30 12200 Berlin - Alemanha. 


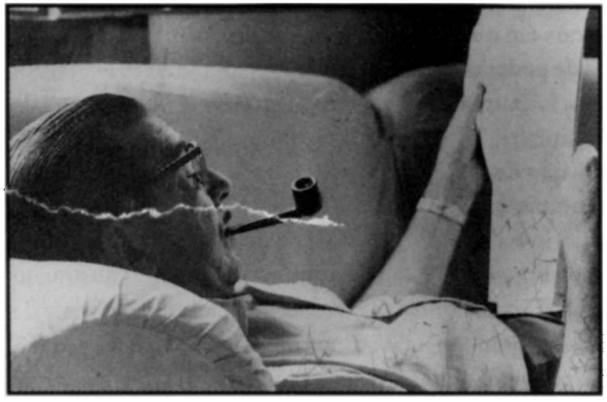

Figura 1. Chegado à fazenda o Professor Portugal deitava na poltrona para ler o jornal. Foto feita pelo estagiário Mario Brock em abril de 1964.

"O sol nasce para todos" passou a ser, desde entāo, uma espécie de senha secreta entre nós dois. Quantas vezes em palestras e em cartas citamos esta frase...

José Ribeiro Portugal saiu de Minas e veio para a então capital do Brasil estudar medicina. Sua carreira foi meteórica. Estava formado aos 25 anos de idade. Doutorou-se em 1926, apenas uma ano após a formatura, e, já em 1929, aos 28, era docente da Cadeira de Medicina Operatória da Faculdade de Medicina da Universidade do Rio de Janeiro com a memorável tese "Contribuiçāo à Neurotomia Retrogasseriana"(Figura 2). Nesta época Portugal já possuia vasta experiência neurocirúrgica e havia desenvolvido a técnica da secçāo intra-dural seletiva da raiz do nervo trigêmeo. Como Cushing, Portugal gostava de ilustrar seus trabalhos com desenhos próprios (Figura 3). Este fato serviu de inspiraçāo e estímulo a mim, jovem estagiário, sempre preocupado em seguir as pegadas do mestre. Guardo ainda, com grande carinho, muitos desenhos que fiz de operaçōes do Professor Portugal, alguns dos quais ele corrigiu de próprio punho (Figuras 4 e 5).

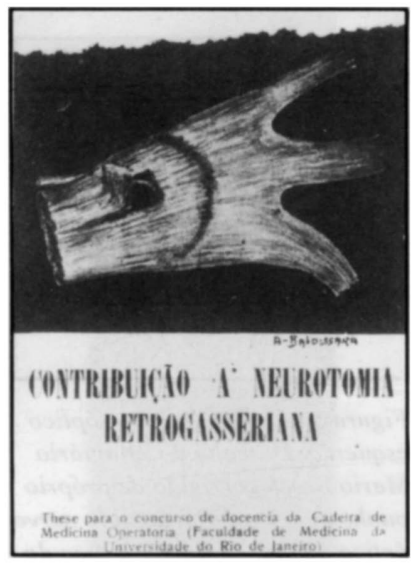

Figura 2. Frontispicio da tese de docência de José Ribeiro Portugal. (O exemplar fotografado tem a capa parcialmente rasgada).
A 4 de abril de 1930 Portugal foi nomeado assistente extranumerário da Cadeira de Medicina Operatória da Faculdade de Medicina do Rio de Janeiro pelo Prof. Benjamim Baptista (Figura 6). Apenas quatro dias mais tarde, a 8 de abril de 1930, o jovem docente apresenta o primeiro currículo neurocirúrgico da história do Brasil (Figura 7).

Em 1931 Portugal publica o opúsculo "Largas Vias de Acesso aos Principais Troncos Vasculares" (Figura 8), uma obra clássica da qual o mestre sempre se orgulhou muitíssimo. Em 1933, quando Portugal tinha apenas 32 anos de idade, assumiu a chefia do recém-criado Serviço de Neurocirurgia do Hospital da Ordem Terceira do Carmo, com cem leitos!

Em 1936 José RIBEIRO Portugal publica o trabalho fundamental sobre "Diagnóstico e Tratamento nas Neuralgias da Face"(Figura 9). Em 1938 aparece o trabalho "Cura Cirúrgica de um Grande Meningioma Com Sinais de Compressāo do Lobo Temporal". Desta vez o autor é José RIBE - e nāo Ribeiro - Portugal (Figura 10). Daí por diante desaparece o nome Ribeiro.

Por que? Por que a adoção do nome "Ribe"? Um dia, na fazenda, eu aprendi a resposta: o Prof. Portugal havia consultado uma vidente e esta lhe havia dito que o número total de letras do nome "Ribeiro" não seria propício ao seu sucesso. Ela o aconselhou a mudar para "Ribe". Assim ficou.

Portugal era torcedor do Vasco da Gama. Amava futebol. Quando havia jogos importantes chegava ao bloco operatório com o seu pequeno rádio de pilhas japonês (marca Spica) que era colocado no parapeito que separava a sala de esterilizaçāo da sala operatória no Instituto de Neurologia da entāo Universidade do Brasil. Quando se fazia necessária a coagulação intraopera tória e éramos obrigados a utilizar o monstruoso coagulador de Bovie, o que produzia um tremendo chiado no rádio de pilhas, Portugal ficava furioso pela interrrupçāo da transmissāo do jogo de futebol e soltava o seu típico e inesquecível: "Oh Senhor!".

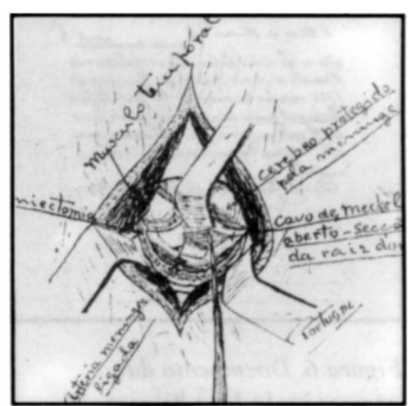

Figura 3. Desenho da autoria de Portugal ilustrando a via de acesso intradural ao ganglio de Gasser. 


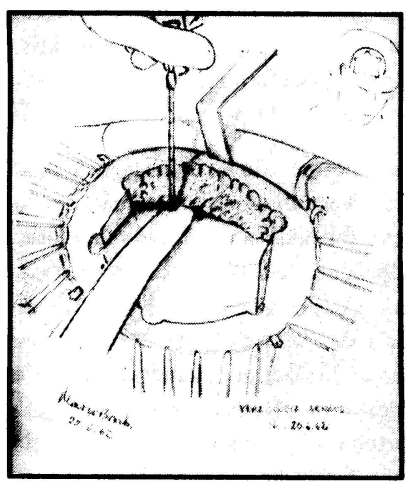

Figura 4. Caso de displasia fibrosa do osso frontal direito. Operação em 20 de junho de 1962.
Durante os anos em que trabalhei com o Professor Portugal tive também, o privilégio de poder acompanhá-lo assiduamente 20 consultório. Lá aprendi muitíssimo. Lá, também, vivi momentos incequeciveis nos quais se revelava o homem simples, bom e entusiasta que ere Portugal! Em 1954, por exemplo, por ocasiāo do Campeonato Mundial de Fuvobol, o dia em que o Brasil jogava contra a Espanha, era dia de consulta do Prof. Portugal. Chegamos ao consultório e a sala de espera estava repleta como de hábito. O Prof. Portugal passou Figura 3. Desenho da autoria de Portugal ilustrando a via de acesso intradural ao Ganglio de Gasser.direto para seu gabinete de consultas, sentou-se à sua grande escravaninha de carvalho maciço, com 3 gavetas de cada lado, em geral repletas de amostras grátis na mais incrivel desordem, ligou o rádio de pilhas, chamou a Maria, uma espécie de enfermeira-arrumadeira-secretária-caixa, e lhe disse que não atenderia ninguém antes do final de jogo. Que esperassem todos. O Brasil , que perdia de $2 \times 0$ ao término do primeiro tempo, acabou ganhando de $4 \times 2$. Portugal chamou a Maria e lhe disse que não cobrasse de ninguém. Nesse dia as consultas foram gratuitas.

Portugal gostava de fumar cachimbo. Portugal gostava de tocar violāo. Portugal gostava das coisas da vida. Portugal tinha um jeito todo especial. Embora desprezasse profundamente a mediocridade, sabia exprimir os seus sentimentos sem machucar.

Os grandes de verdade sāo, também, magnânimes e nada têm a temer. Uma de suas características primordiais é o verdadeiro carinho pelos discípulos, que não são considerados como escravos mas sim como filhos herdeiros muito queridos e respeitados. Portugal sabia não apenas fazer com que cada um de nós se sentisse um príncipe herdeiro, mas também com que cada príncipe herdeiro se sentisse membro de uma imensa família real. A melhor descriçāo do espírito que nos unia é feita pelo próprio mestre em uma carta que me escreveu em 1991: "Na realidade, no meu serviço nāo havia mestre nem discípulos. Havia, sim, bons amigos e colaboradores eficientes, inteligentes e responsáveis"... (Figura 11).

Cada geraçāo de discípulos aprendia a conhecer o nome e a honrar as geraçöes precedentes, sempre ciente de que a família aumentava de ano a ano: Santos Machado, Jaime Viana, Renato Barbosa, Mario Coutinho, Pedro Sampaio, Francisco Guerra, Otoide Pinheiro e, "last but not least", o

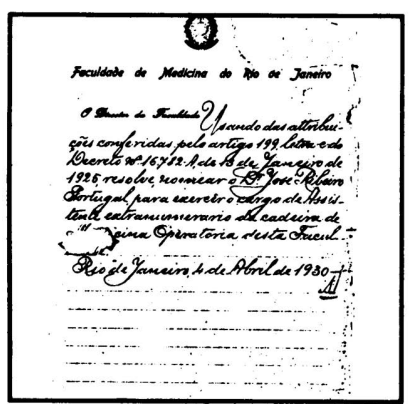

Figura 6. Documento da nomeação de José Ribeiro Portugal como assistente extranumerário da Cadeira de Medicina Operatória da Janeiro em 4 de abril de 1930. Faculdade de Medicina do Rio de meu querido amigo e mestre

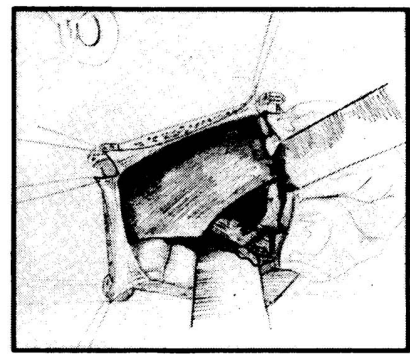

Figura 5. Glioma do nervo óptico esquerdo. Desenho do estagiário Mario Brock corrigido de próprio punho pelo Prof. Portugal (o nervo óptico afetado era mais grosso do que desenhado pelo estagiário). Feliciano Pinto, o homem que colocou o primeiro bisturi em minha mão, antes ainda que eu fosse trabalhar com o Professor Portugal, são apenas alguns dos muitos nomes que aprendi a venerar. A minha veneraçāo com relação a todos esses membros de minha estirpe neurocirúrgica nada perdeu em intensidade com o decorrer dos anos.

Em 1948, já prestigiadíssimo em sua pátria, Portugal foi pela primeira vez aos Estados Unidos. Visitou vários serviços e ficou particularmente impressionado com o serviço de James Gardner, para onde mandou, mais tarde, o seu sobrinho, o saudoso José Portugal Pinto (o "Portugalzinho").

Portugal foi um dos neurocirurgiōes mais habilidosos de quantos eu tive a ventura de observar em minha vida. Presenciei neurotomias retrogasserianas em 18 minutos de pele a pele. Mas o mestre me disse haver feito colecistectomias em 32 minutos!

Aos 91 Portugal era mais jovem de espírito, mais entusiasta, mais cheio de projetos e mais sequioso de saber do que muito jovem que hoje começa a sua carreira. 


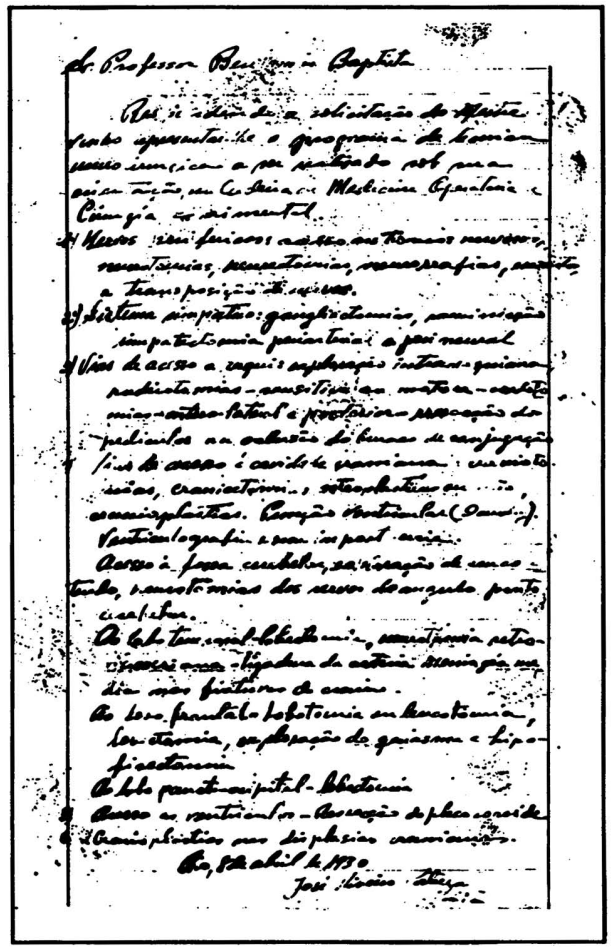

Figura 7. Primeiro currículo neurocirúrgico do Brasil. Notem-se (ponto 3) as várias vias de acesso ao raque e ao cérebro.
Em sua última mensagem falada à mim (nós nos correspondiamos através de fitas sonoras gravadas) pedia-me informaçōes e separatas sobre os meningeomas císticos. Estava estudando com afinco o problema e preparando uma publicação a respeito. Mandei ao Professor Portugal todas as informaçöes pedidas e, também, um grande número de fotocópias de trabalhos sobre 0 assunto, que obtive na Biblioteca de minha Faculdade. Este material serviu de base para a última e memorável aula que o Professor Portugal proferiu em sua vida, por ocasiāo do Congresso da Academia Brasileira de Neurocirurgia em 1992. Foi a última vez que falou em público a voz mais eloquente da neurocirurgia brasileira!

\section{Meu querido Prof. Portugal!}

Bem imagimo que o senhor está feliz em ver que nós todos, que tanto aprendemos do senhor, que tanto o veneramos, que sentimos a sua presença continuada, estamos reunidos uma vez mais em torno à sua pessoa.

O senhor se lembra, Porf. Portugal, o que o senhor dizia quando um tumor difícil era vencido pela sua experiência e habilidade? O senhor se voltava para o assistente, que acompanhava deslumbrado os seus gestos seguros e elegantes e, com aquele seu olhar vitorioso mas sempre modesto, dizia a frase tāo típica, que se tomou quase um lema para todos nós: "Menino", dizia o senhor, "isto aqui está tāo bonito que até parece fácil.

O senhor sempre estará presente entre nós. $O$ senhor escreveu com tinta indelével as primeiras páginas da história da Neurocirurgia Pátria. O senhor é o verdadeiro pai da Neurocirurgia Brasileira. As suas realizaçōes, os seus esforços, o seu gênio e ao mesmo tempo a sua bondade simples, constituirăo para todas as geraçōes futuras de neurocirurgiōes brasileiros um compromisso solene de dedicaçāo aos ideais aos quais o senhor serviu de maneira tâo devota e exemplar.

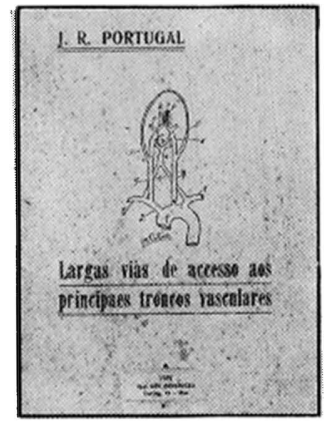

Figura 8. "Largas vias de acesso aos principaes troncos vasculares". As ilustrações são do próprio autor.

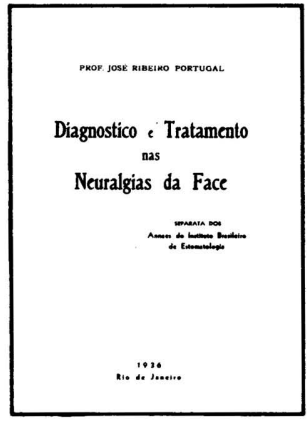

Figura 9. Última publicação de José Ribeiro Portugal.

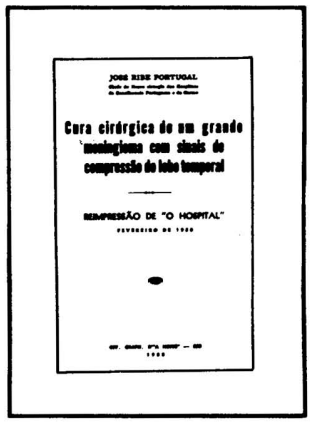

Figura 10. Primeira publicação de José Ribe Portugal. 


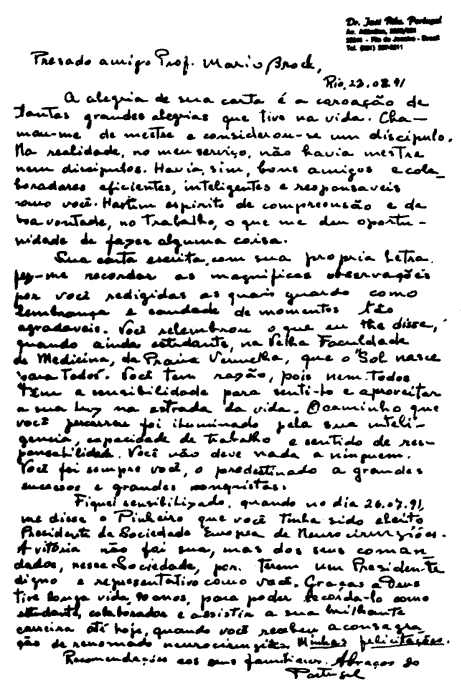

Figura 11. Carta de Portugal ao autor em 22.8.1991. A tenceira frase do primeiro parágrafo define a atmosfera na equipe do Professor Portugal.

Aqui estamos para levar avante a chama da Neurocirurgia Brasileira.

\section{Meu querido Professor Portugal!}

Em sua última mensagem falada o senhor se despediu com um "Até a vista!".

Sim, Professor Portugal, não há dúvida de que nos reveremos. Continuaremos todos, o mestre e os discípulos, "além, muito além daquelas serras que ainda azulam no horizonte" a tratar de temas neurocinúrgicos. Discutiremos anatomia, falaremos das coisas da vida passada e futura. Continuaremos tecendo projetos já então para a eternidade. Escreveremos conjuntamente todos os artigos que näo tivemos tempo de publicar. Teremos todos os instrumentos cirúrgicos que sempre sonhamos possuir. Todos os diagnósticos serão claros, todos os doentes serāo curáveis. Todos os nossos sonhos se confundirāo, enfim, com a realidade, tornando indistinguíveis os anseios $e$ as realizações. Continuaremos em outros moldes e em outras escalas a felicidade e o sentimento de gratificaçāo que sempre nos proporcionou (a nós, sonhadores inveterados e incorrigíveis) a Neurocirurgia. Esta Neurocirurgia a qual o senhor, querido Professor Portugal, devotou toda uma vida. Esta Neurocirurgia que servirá de estímulo e de refúgio a tantas geraçōes futuras de neurocirurgiōes brasileiros.

Professor Portugal! O que eu quero dizer em nome dos aqui presentes é o seguinte: o seu esforço, o seu entusiasmo, a sua dedicaçăo e o seu carinho nāo foram em vão.

Até a vista, mestre querido! 